\title{
Isolation and Characterization of Multiple Antibiotic Resistant A. hydrophila causing Mortality of Indian Major Carps in Ganjam District, Odisha
}

\author{
P. Chandravanshi, S. K. Udgata, J. Kumari, B. Sahu* and N. C. Pashupalaka \\ College of Fisheries (OUAT), Rangailunda, Berhampur, Odisha, India \\ *Corresponding author
}

\section{A B S T R A C T}

\section{Keywords}

Aeromonas hydrophila, Aeromoniasis, Antibiotic resistance, Molecular characterization, Phylogenetic analysis

\section{Article Info}

Accepted: 07 November 2020 Available Online: 10 December 2020
The study was conducted to identify and characterize the etiological agent causing disease and mortality in Indian major carp from fresh water fish farms of Ganjam district in Odisha, India. Diseased fish samples showing symptoms of haemorrhages, red sores, ulcerations, loss of appetite, lethargy, pop-eyes, dropsy and tail or fin rots etc. were collected for the isolation and identification of the pathogenic bacteria using microbiological, biochemical and molecular methods. Out of 65 samples collected, 33 presumptive Aeromonas isolates were obtained, which were then pooled to 12 isolates for further analysis based on their source of isolation. The 16S rRNA gene sequencing and phylogenetic analysis of three isolated strains showed close relationship with Aeromonas hydrophila. In Antibiogram study, all three strains were found resistant against more than three commonly used antibiotics having MAR index $\geq 0.5$. This study highlights the involvement of multiple antibiotic resistant Aeromonas hydrophila in the disease outbreak of cultured Indian major carps. The study further affirms the superiority of molecular characterization in identifying Aeromonas hydrophila over microbiological and biochemical methods.

\section{Introduction}

Aquaculture has been recognized as one of the fastest growing food producing sector in the world. The significant contribution of aquaculture over the past few decades has been able to place India in second position in terms of global inland fish production (FAO, 2018). While aiming at maximizing fish production, fish farms in India are expanding and intensifying their culture system and hence among other reasons, disease outbreak has started to become a disaster in recent days. Disease has emerged out as one of the major limiting factors for development and management of aquaculture in India and many other countries of the world (Kumar et al., 2016).

Out of many diseases, bacterial diseases are the most leading causes of fish mortality in aquaculture farms (Leung and Bates, 2013). Aeromoniasis is an endemic bacterial disease caused by Aeromonads, and is a world-wide 
problem affecting many fishes (Robinson et al., 2014). These aeromonads include Aeromonas hydrophila, Aeromonas caviae, Aeromonas sobria, Aeromonas veronii etc. Aeromonas sp is ubiquitous, free living, gram negative, motile rod that causes multiple infections in fish with varied symptoms including skin haemorrhages, red sores, body ulcerations, loss of appetite, lethargy, popeyes, dropsy and tail or fin rots etc. (Hu et al., 2012; Sreedharan et al., 2012).

The disease is often associated with serious damages and economic losses in fish farming industry (Yang et al., 2017). Aeromonas sp is also an opportunistic pathogen of a wide variety of hosts including human beings (Samal et al., 2014).

Antimicrobial drug therapy is the most widely used method of control of Aeromoniasis in fish culture farms (Guz and Kozińska, 2004). However, the main problem in the use of antibiotics against Aeromonas infection is the development of resistance by these bacteria to these antibiotics (Sarder et al., 2016). Besides, the massive use of antimicrobials at sub-optimal doses as growth promoters in aquaculture farms encourages the natural emergence of bacterial resistance towards the antimicrobials (Chu and Zhu, 2010; FDA, 1998).

Resistance of Aeromonas sp. to commonly used antibiotics is an emerging problem in aquaculture. Repeated reports on multidrug resistance in the genus Aeromonas is a great concern today (Albert et al., 2000; Vivekanandhan et al., 2002; Palu et al., 2006; Lijon et al., 2015; Sarder et al., 2016), since the increase in resistance increases the difficulty in treating such diseases in fishes. The situation becomes grave when such strain is zoonotic in nature and involved in human infections. So, the present study was done to identify the etiological agent in diseased Indian major carps in fresh water fish farms of Ganjam district in Odisha, India and to establish their antibiotic resistance pattern.

\section{Materials and Methods}

\section{Collection of diseased fish sample}

Randomly selected twelve freshwater fish farms across Ganjam district in Odisha were sampled using cast net for collection of diseased fish samples during January to March 2019. The moribund fish samples of catla (Catla catla), rohu (Labeo rohita), mrigal (Cirrhinus mrigala), calbasu (Labeo calbasu) and common carp (Cyprinus carpio) with signs of haemorrhage, ulceration, abdominal swelling, erosion of fin and tail etc. were collected. External sores or lesions were immediately swabbed using sterile cotton swab (Hi-Media) and inoculated into sterile Tryptic Soy Broth (TSB, Hi-Media) aseptically. Tissue samples of external and internal organs like skin, fin, gill, kidney, liver and intestine etc. were collected by dissecting the moribund fish at pond site and inoculated into TSB aseptically following protocols of Pradhan et al., (2014). The samples were then brought to the laboratory under ambient condition for further bacteriological analysis.

\section{Bacteriological examination}

Upon arrival at the laboratory, the inoculated broths were incubated at $30^{\circ} \mathrm{C}$. Next day, the overnight cultures were serially diluted upto $10^{-6}$ and $100 \mu \mathrm{l}$ each from last three dilutions were spread plated on Rimler Shotts (RS) Agar medium in duplicate and incubated at $30^{\circ} \mathrm{C}$ for $24 \mathrm{~h}$.

Isolated colonies appearing slightly convex, mucoid and yellowish in colour were presumed to be Aeromonas hydrophila (Sahoo and Das, 2014), and hence subcultured onto Tryptic Soy Agar (Hi-Media) slants for further analysis. 


\section{Biochemical characterization}

All the presumptive isolates were characterised morphologically (Gram's staining, shape and motility) and subjected to set of biochemical test meant for $A$. hydrophila such as, Indole, Methyl red (MR), Voges Proskauer (VP), Citrate utilization (IMViC reaction), Oxidase, Catalase, Oxidation-Fermentation, Triple Sugar Iron (TSI) and Amino Acid Decarboxylase test for Arginine, Lysine and Ornithine (Khuntia, 2011; Sahoo and Das, 2014; Monir et al., 2016). The Reference strain A. hydrophilla (MTCC 1739) was used as positive control while testing the presumptive isolates.

\section{Molecular identification}

Presumptive isolates showing deviation to some of the biochemical tests as compared against standard reference strain were subjected to molecular identification. The genomic DNA from these selected isolates were extracted using the DNeasy UltraClean Microbial Kit (QIAGEN, Germany) as per manufacturer's instruction. The 16S rRNA genes from the pathogenic isolate was then amplified by PCR using a pair of universal primers, 27f (5'-AGAGTTTGATCCTG GCTCAG-3') and 1492r (5'-CGGTTACCT TGTTACGACTT-3') according to Cao et al., (2010) and Kupfer et al., (2006). Sequencing was performed by the fluorescent-labeled dideoxynucleotides termination method (with a BigDye terminator) on ABI 3730 XL DNA Sequencer (Applied Biosystems, Waltham, MA, USA) using BDT v3.1 cycle sequencing kit and another pair of primers, forward (5'GGATTAGATACCCTGGTA-3') and reverse (5'-CCGTCAATTCMTTTRAGTTT3 '). Consensus sequence of 16S rRNA gene was generated from forward and reverse sequence data using aligner software. Homology searches for 16S rRNA gene sequences were performed using the Basic Local Alignment Search Tool (BLAST) version 5 software (National Library of Medicine, Bethesda, MD, USA) available at the National Center for Biotechnology Information (NCBI).

Based on maximum identity score first ten sequences were selected and few distantly related sequences were aligned using multiple alignment software program Clustal $\mathrm{W}$ in MEGAx (Kumar et al., 2018) and the phylogenetic analysis was performed by using the Maximum likelihood method based on the Kimura 2-parameter model.

Antibiotic sensitivity study of the Aeromonas hydrophila isolates

Antibiogram profile of the confirmed Aeromonas hydrophila isolates was done using ten commonly used antibiotics. The details of antibiotics used in the present study have been given in the Table 1 .

The antibiotic sensitivity test was performed using Kirby Bauer Disc Diffusion Method (Bauer et al., 1966; Jorgensen and Ferraro, 2009) following Clinical and Laboratory Standards Institute guidelines (CLSI, 2018). Briefly, the test was performed on Mueller Hinton Agar plates for all the Aeromonas isolates against the selected antibiotics. Zone of inhibition was measured, recorded and interpreted as Susceptible (S), Intermediate (I) and Resistant (R) by considering Enterobacteriaceae breakpoints (Lamy et al., 2012). MAR index was calculated as the ratio of number of resistant phenotype to total number of antimicrobials to which the strains were exposed (Hossain et al., 2017).

\section{Results and Discussion}

Isolation of Aeromonas hydrophila from diseased fish

Sample collection of diseased fishes was done from 12 fish farms of Ganjam district, Odisha. 
Out of which disease outbreak was seen in 3 farms located at Aska, Duba and Chatrapur, from which a total of 65 samples were collected from gill, skin, fin, liver, kidney and intestine of live and moribund fishes of Indian major carps (Fig. 2). Out of which, 33 isolates were able to grow on Rimler Shott's Agar medium producing slightly convex, mucoid and yellowish colonies. Different researchers have used different media for presumptive isolation of Aeromonas hydrophila from aquatic animals, aquatic environment, seafoods, animal products, fishes and humans like Rimler-Shotts medium (RS), Starch Ampicillin agar (SA), Starch-GlutamateAmpicillin-Penicillin-based medium (SGAP10C) and Pseudomonas Aeromonas selective agar base (GSP) (Shotts and Rimler, 1973; Jenkins and Taylor, 1995; Singh, 1997). In this study, we have used RS medium as selective medium for presumptive isolation of Aeromonas hydrophila by following methods of Sahoo and Das (2014). All the 33 presumptive Aeromonas isolates were pooled, considering single isolate responsible for manifestation of disease in a fish affecting multiple organs, to 12 isolates based on their source of isolation for further analysis.

\section{Biochemical characterization of presumptive Aeromonas hydrophila isolates}

All the 12 pooled isolates were subjected to different biochemical tests besides Gram staining and motility test along with the reference strain of Aeromonas hydrophila (MTCC 1739) as positive control. The isolate wise detailed result of biochemical tests has been depicted in Table 2. In this study, majority of the isolates were found to be Gram negative, motile, rod shaped, able to produce indole from tryptophan, utilised glucose to produce different acid by mixed acid pathway, but not able to follow butylene glycol pathway, utilized citrate as sole carbon source, produced cytochrome oxidase, were fermentative, able to utilize glucose, had lysine and arginine decarboxylase enzyme but not ornithine decarboxylase enzyme (Table 2). Many authors have performed similar biochemical test for Aeromonads along with many other tests like acid production from maltose, manitol, esculin, starch and gelatin hydrolysis, sensitivity to vibrostatic agent $\mathrm{O} / 129$, Nitrate reduction, growth at different temperature and salt concentration etc. and have got almost similar results like the present study with minor variations (Ashiru et al., 2011; Jeeva et al., 2013; Ali et al., 2014; Laith and Najiah, 2014; Samal et al., 2014; Thiyagarajan et al., 2014; Lijon et al., 2015; Monir et al., 2016; Nahar et al., 2016).

Few of the isolates showed deviations in some of the characteristic reactions compared to the reference strain A hydrophila (MTCC 1739), which has been described below. Almost all the isolates showed positive reaction towards MR test as evidenced by red coloration in culture tube after addition of methyl red reagent that showed production of mixed acid. However, only one isolate i.e., Ah7 showed negative reaction to this test. Our findings are in agreement with Jeeva et al., (2013); Samal et al., (2014); Thiyagarajan et al., (2014); Lijon et al., (2015), who have reported positive reaction towards MR test, while Ali et al., (2014); Monir et al., (2016); Rawal et al., (2016), very few isolates of Laith and Najiah, (2014) and Samal et al., (2014) have reported negative reaction to MR test as the characteristic reactions for Aeromonas hydrohila. Similarly, VP test was performed to detect acetoin production following butylene glycol pathway by addition of Barritt's reagent A and $\mathrm{B}$. While majority of our isolates have shown negative reaction towards VP test, similar to that has been reported only by Samal et al., (2014), few of our $A$ hydrophila isolates namely $A h 2, A h 7$ and $A h 9$ have shown positive reaction as well. Positive reactions of $A$ hydrophila towards 
VP test has been reported by the previous researchers like Jeeva et al., (2013); Ali et al., (2014); Laith and Najiah, (2014); Thiyagarajan et al., (2014); Lijon et al., (2015); Monir et al., (2016); Nahar et al., (2016); Rawal et al., (2016). In the case of Citrate utilization, majority of the isolates showed positive reaction, as has been reported by Laith and Najiah, (2014); Samal et al., (2014); Thiyagarajan et al., (2014); Lijon et al., (2015); Monir et al., (2016); Nahar et al., (2016), while three isolates namely $A h 2, A h 4$ and $A h 7$ were unable to utilize citrate as sole carbon source. Similar to this finding Rawal et al., (2016), few isolates of Awan et al., (2005) and Samal et al., (2014) have reported negative reaction towards citrate utilization test.

Aeromonas isolates are capable of utilising glucose as shown by colour changes in TSI slant as red for alkaline nature and yellow for acidic nature in the butt due to anaerobic oxidation. Positive result for TSI is interpreted as K/A for alkaline slant and acidic butt and negative result as A/A for acidic slant and acidic butt.

Majority of the isolates in this study have shown positive result for TSI in agreement with the findings of Nahar et al., (2016), Monir et al., (2016) and Samal et al., (2014). However, three isolates namely $A h 2, A h 7$ and Ah9 showed negative result for TSI test, which has also been reported by Samal et al., (2014), Laith and Najiah (2014).

Aeromonas group of microorganism can be identified and characterized up to genus level on the basis of amino acid utilization (Janda and Abbott, 2010). Majority of our isolates were capable of utilizing lysine and arginine due to presence of specific decarboxylase enzyme as has been reported by Abbott et al., (2003); Jeeva et al., (2013); Samal et al., (2014); Nahar et al., (2016).

On the other hand, Monir et al., (2016), few isolates of Samal et al., (2014) have reported absence of lysine decarboxylase enzyme. Absence of arginine decarboxylase enzyme was observed for three of our $A$ hydrophila isolates namely, $A h 3, A h 7$ and $A h 9$, that corroborates the findings for few isolates by Samal et al., (2014). To summarise, all presumptive isolates; except three namely, Ah2, $A h 7$ and $A h 9$; have shown the characteristic biochemical reactions similar to the standard reference strain $A$ hydrophila MTCC 1739, and hence can be confirmed as A hydrophila.

\section{Molecular identification}

The PCR amplified 16S rRNA gene sequence of pathogenic isolates $A h 2, A h 7$ and $A h 9$; that were showing many deviations in biochemical tests from the standard reference strain; were sequenced, analyzed and submitted to GenBank (GenBank Accession No MT974689.1, MT974690.1 and MT974691.1). The BLAST analysis of the $16 \mathrm{~S}$ rRNA gene sequence of $A h 2$ showed $100 \%$ similarity with Aeromonas hydrophila strain CCM 7232 (GenBank Accession No. NR_043638.1) and JCM 1027 (GenBank accession no. NR_113342.1). At the same time, that of $A h 7$ and $A h 9$ showed $100 \%$ and 99.73\% sequence similarities with Aeromonas hydrophila strain ATCC 7966 (GenBank Accession No. NR_118944.1) respectively. Accordingly, the molecular identification results confirmed that the isolated bacterial fish pathogen are A. hydrophila. 
Table.1 Particulars of antibiotics used in the present study

\begin{tabular}{|c|c|c|c|}
\hline SI. No. & Antibiotics & Disc content $(\mathbf{m c g})$ & Class \\
\hline $\mathbf{0 1}$ & Ciprofloxacin & $5 \mathrm{mcg}$ & Fluroquinolones $2 \mathrm{G}$ \\
\hline $\mathbf{0 2}$ & Ofloxacin & $5 \mathrm{mcg}$ & Fluroquinolones $2 \mathrm{G}$ \\
\hline $\mathbf{0 3}$ & Norfloxacin & $10 \mathrm{mcg}$ & Fluroquinolones $2 \mathrm{G}$ \\
\hline $\mathbf{0 4}$ & Streptomycin & $10 \mathrm{mcg}$ & Aminoglycosides \\
\hline $\mathbf{0 5}$ & Gentamicin & $10 \mathrm{mcg}$ & Aminoglycosides \\
\hline $\mathbf{0 6}$ & Tetracycline & $30 \mathrm{mcg}$ & Tetracyclines \\
\hline $\mathbf{0 7}$ & Azithromycin & $15 \mathrm{mcg}$ & Macrolides \\
\hline $\mathbf{0 8}$ & Penicillin & $10 \mathrm{units}$ & Penicillin \\
\hline $\mathbf{0 9}$ & Ampicillin & $10 \mathrm{mcg}$ & Aminopenicillin \\
\hline $\mathbf{1 0}$ & Amoxyclav & $30 \mathrm{mcg}(20 / 10)$ & $\begin{array}{c}\text { Aminopenicillin+ }+\beta \\
\text { lactam inhibitor }\end{array}$ \\
& Amoxycillin/ & & \\
\hline & Clavulanic acid) & & \\
\hline
\end{tabular}

Table.2 Biochemical characterization of presumptive Aeromonas isolates from diseased fish samples

\begin{tabular}{|c|c|c|c|c|c|c|c|c|c|c|c|c|c|c|}
\hline \multirow{2}{*}{$\begin{array}{l}\text { Sl. } \\
\text { No }\end{array}$} & \multirow[t]{2}{*}{ Test } & \multicolumn{12}{|c|}{ Aeromonas Isolates } & \multirow{2}{*}{$\begin{array}{c}\text { A.h. } \\
\text { MTCC } \\
1739\end{array}$} \\
\hline & & Ahl & Ah2 & Ah3 & Ah4 & Ah5 & Ah6 & $A h 7$ & Ah8 & Ah9 & Ah10 & Ah11 & Ah12 & \\
\hline 1. & Motility & $+v e$ & -ve & $+v e$ & $+v e$ & +ve & +ve & -ve & +ve & +ve & $+\mathrm{ve}$ & $+\mathrm{ve}$ & +ve & +ve \\
\hline 2. & Gram staining & -ve & -ve & -ve & - ve & -ve & -ve & -ve & -ve & - ve & -ve & -ve & -ve & -ve \\
\hline 3. & Morphology & Rod & Rod & Rod & Rod & Rod & Rod & Rod & Rod & Rod & Rod & Rod & Rod & Rod \\
\hline 4. & Indole & $+\mathrm{ve}$ & -ve & $+\mathrm{ve}$ & +ve & +ve & +ve & -ve & +ve & +ve & $+\mathrm{ve}$ & $+\mathrm{ve}$ & $+\mathrm{ve}$ & $+\mathrm{ve}$ \\
\hline 5. & Methyl Red & $+v e$ & + ve & $+\mathrm{ve}$ & $+v e$ & +ve & +ve & -ve & +ve & +ve & +ve & + ve & +ve & +ve \\
\hline 6. & $\begin{array}{l}\text { Voges - } \\
\text { Proskauer }\end{array}$ & -ve & $+v e$ & -ve & -ve & -ve & -ve & $+v e$ & -ve & $+v e$ & -ve & -ve & -ve & -ve \\
\hline 7. & $\begin{array}{l}\text { Citrate } \\
\text { utilization }\end{array}$ & $+v e$ & -ve & $+v e$ & -ve & +ve & $+v e$ & -ve & $+v e$ & +ve & $+v e$ & $+\mathrm{ve}$ & $+v e$ & $+v e$ \\
\hline 8. & Oxidase & $+v e$ & +ve & $+v e$ & +ve & +ve & +ve & $+v e$ & $+v e$ & +ve & + ve & $+\mathrm{ve}$ & +ve & $+v e$ \\
\hline 9. & Catalase & $+v e$ & -ve & $+\mathrm{ve}$ & +ve & +ve & +ve & -ve & +ve & -ve & $+\mathrm{ve}$ & $+\mathrm{ve}$ & +ve & $+v e$ \\
\hline 10. & $\begin{array}{l}\text { Oxidation / } \\
\text { Fermentation }\end{array}$ & $+/+$ & $+/+$ & $+/+$ & $+/+$ & $+/+$ & $+/+$ & $+/+$ & $+/+$ & $+/+$ & $+/+$ & $+/+$ & $+/+$ & $+/+$ \\
\hline 11. & $\begin{array}{l}\text { Triple sugar } \\
\text { iron }\end{array}$ & $\mathrm{K} / \mathrm{A}$ & $\mathrm{K} / \mathrm{K}$ & $\mathrm{K} / \mathrm{A}$ & $\mathrm{K} / \mathrm{A}$ & $\mathrm{K} / \mathrm{A}$ & $\mathrm{K} / \mathrm{A}$ & $\mathrm{K} / \mathrm{K}$ & $\mathrm{K} / \mathrm{A}$ & $\mathrm{K} / \mathrm{K}$ & $\mathrm{K} / \mathrm{A}$ & $\mathrm{K} / \mathrm{A}$ & $\mathrm{K} / \mathrm{A}$ & $\mathrm{K} / \mathrm{A}$ \\
\hline 12. & Arginine & $+v e$ & -ve & $+v e$ & +ve & +ve & +ve & -ve & +ve & -ve & $+\mathrm{ve}$ & $+\mathrm{ve}$ & $+\mathrm{ve}$ & $+v e$ \\
\hline 13. & Lysine & $+v e$ & $+\mathrm{ve}$ & $+v e$ & +ve & +ve & +ve & $+v e$ & +ve & $+\mathrm{ve}$ & $+\mathrm{ve}$ & $+\mathrm{ve}$ & +ve & +ve \\
\hline 14. & Ornithine & -ve & -ve & -ve & - ve & -ve & -ve & -ve & -ve & -ve & -ve & -ve & -ve & -ve \\
\hline
\end{tabular}


Table.3 Antibiogram profile of $A$. hydrophila $(\mathrm{n}=3)$ isolates against different antibiotics

\begin{tabular}{|c|c|c|c|c|c|c|c|c|}
\hline \multirow[t]{2}{*}{ Sl. No. } & \multirow[t]{2}{*}{ Antibiotics } & \multirow{2}{*}{$\begin{array}{l}\text { Disk content } \\
\text { ( mcg) }\end{array}$} & \multirow[t]{2}{*}{$A h 2$} & \multirow[t]{2}{*}{ Ah 7} & \multirow[t]{2}{*}{$A h 9$} & \multicolumn{3}{|c|}{ Percentage } \\
\hline & & & & & & Sensitive & Intermediate & Resistant \\
\hline 1 & Ciprofloxacin & 5 & $\mathrm{~S}$ & $\mathrm{~S}$ & $\mathrm{~S}$ & 100 & 0 & 0 \\
\hline 2 & Ofloxacin & 5 & S & $\mathrm{S}$ & S & 100 & 0 & 0 \\
\hline 3 & Norfloxacin & 10 & S & $\mathrm{S}$ & S & 100 & 0 & 0 \\
\hline 4 & Streptomycin & 10 & I & $\mathrm{S}$ & I & 33.3 & 66.67 & 0 \\
\hline 5 & Gentamicin & 10 & $\mathrm{~S}$ & $\mathrm{~S}$ & $S$ & 100 & 0 & 0 \\
\hline 6 & Tetracycline & 30 & $\mathrm{R}$ & $\mathrm{R}$ & $\mathrm{R}$ & 0 & 0 & 100 \\
\hline 7 & Azithromycin & 15 & $\mathrm{R}$ & I & I & 33.3 & 66.67 & 0 \\
\hline 8 & Penicillin & 10 units & $\mathrm{R}$ & $\mathrm{R}$ & $\mathrm{R}$ & 0 & 0 & 100 \\
\hline 9 & Ampicillin & 10 & $\mathrm{R}$ & $\mathrm{R}$ & $\mathrm{R}$ & 0 & 0 & 100 \\
\hline 10 & Amoxyclav & $20 / 10$ & $\mathrm{R}$ & $\mathrm{R}$ & $\mathrm{R}$ & 0 & 0 & 100 \\
\hline & \multicolumn{2}{|c|}{$\mathbf{R} / \mathrm{I} / \mathrm{S}$} & $5 / 1 / 4$ & $4 / 1 / 5$ & $4 / 2 / 4$ & & & \\
\hline & \multicolumn{2}{|c|}{ MAR index } & 0.5 & 0.4 & 0.4 & & & \\
\hline
\end{tabular}

Fig.1 Evolutionary analysis by Maximum Likelihood method

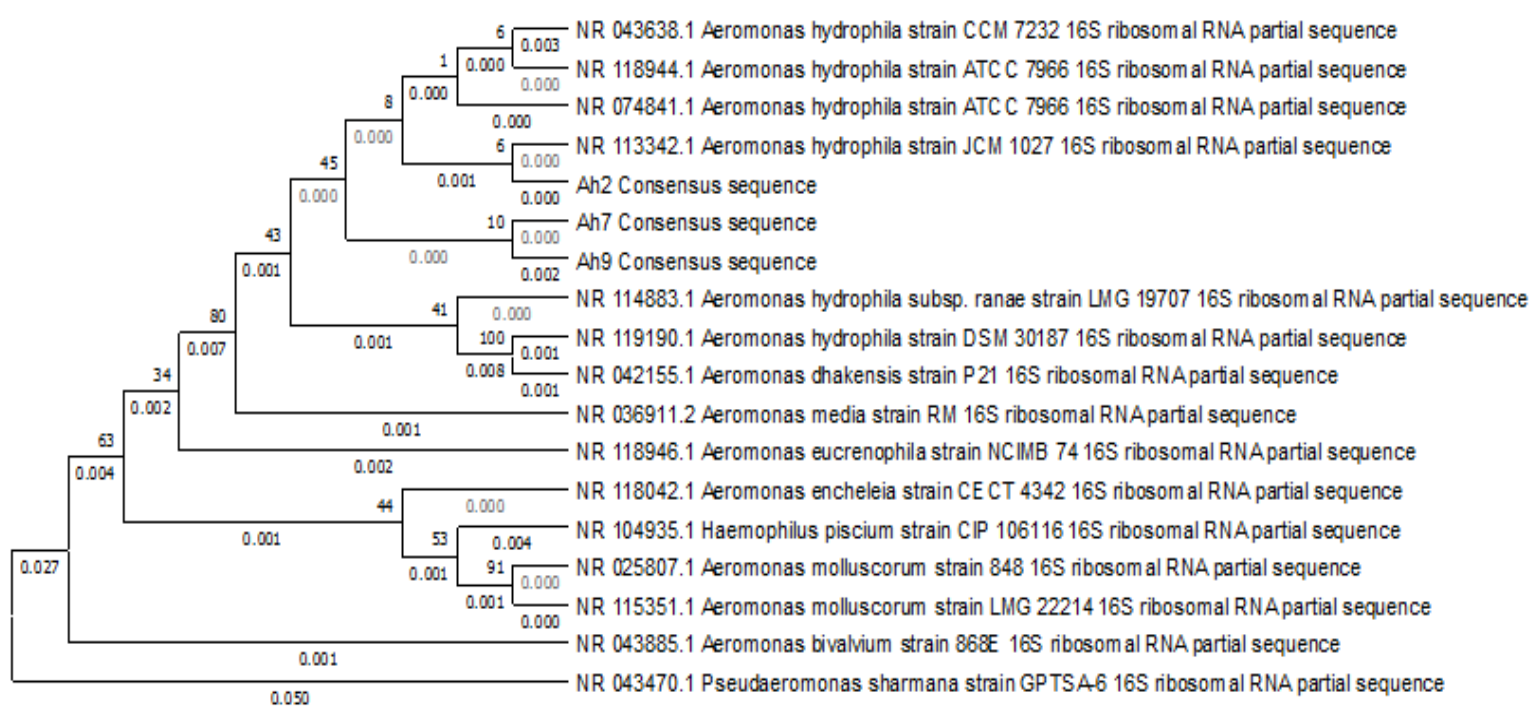

The evolutionary history was inferred by using the Maximum Likelihood method and Kimura 2-parameter model (Kimura, 1980). The tree with the highest log likelihood (-2862.32) is shown. The percentage of trees in which the associated taxa clustered together is shown next to the branches. Initial tree(s) for the heuristic search were obtained automatically by applying Neighbor-Join and BioNJ algorithms to a matrix of pairwise distances estimated using the Maximum Composite Likelihood (MCL) approach, and then selecting the topology with superior log likelihood value. A discrete Gamma distribution was used to model evolutionary rate differences among sites ( 5 categories $(+G$, parameter $=0.0646))$. The rate variation model allowed for some sites to be evolutionarily invariable $([+I]$, $51.44 \%$ sites). This analysis involved 18 nucleotide sequences. Codon positions included were $1 \mathrm{st}+2 \mathrm{nd}+3 \mathrm{rd}+$ Noncoding. There were a total of 1545 positions in the final dataset. 
Fig.2 Fishes infected with A. hydrophila

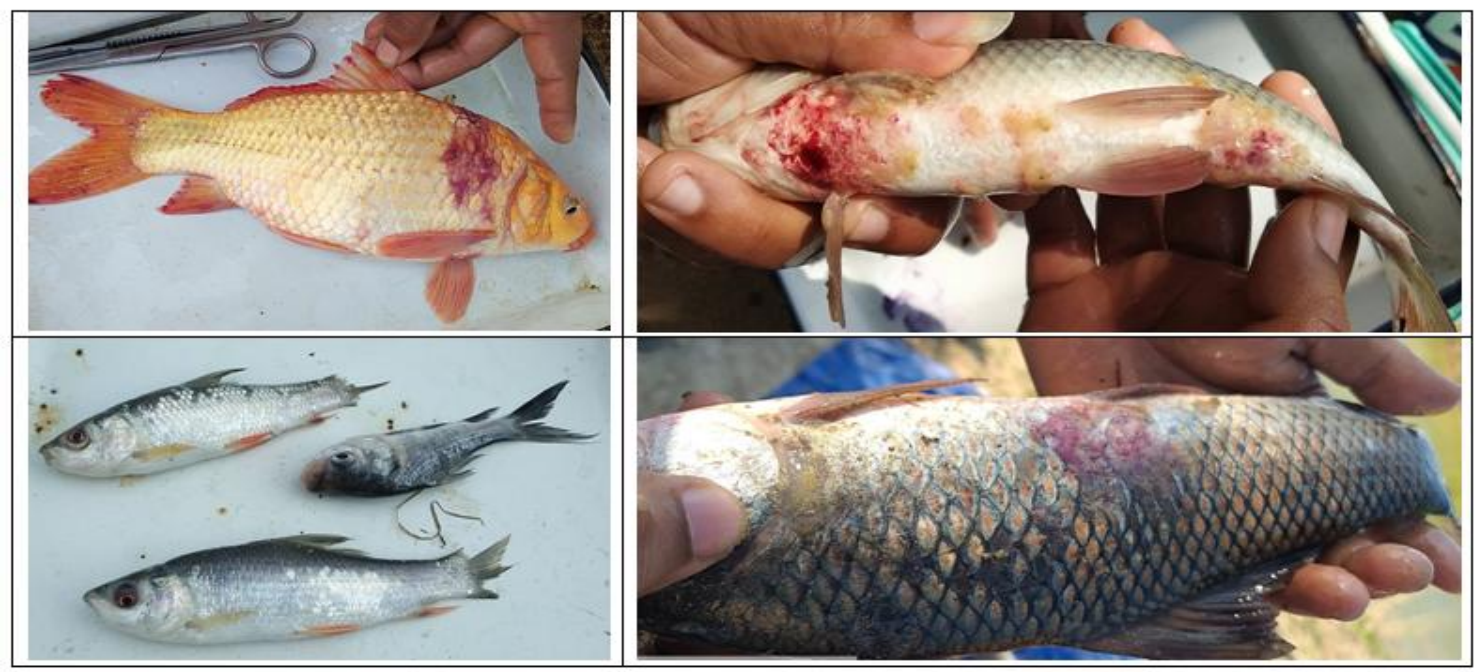

\section{Phylogenetic analysis}

The phylogenetic cladogram was constructed using maximum likelihood algorithm. It revealed the relationship of the isolate $A h 2$, $A h 7$ and $A h 9$ with other Aeromonas species. The fifteen other 16S rRNA gene sequences homologous to A. hydrophila were obtained from NCBI GenBank. The phylogenetic cladogram revealed that $16 \mathrm{~S}$ rRNA gene sequence of $A h 2, A h 7$ and $A h 9$ are evolutionarily very close to $16 \mathrm{~S}$ rRNA gene of $A$. hydrophila with highest bootstrap value (Fig. 1).

\section{Antibiotic sensitivity study of $A$. hydrophila isolates}

The antibiogram analysis of three isolates namely $A h 2, A h 7$ and $A h 9$; that were confirmed as $A$. hydrophila through molecular methods; showed $100 \%$ susceptibility to Fluroquinolone class of antibiotics namely, Ciprofloxacin, Ofloxacin, Norfloxacin and Gentamicin (Aminoglycosides). Intermediate response was observed towards Streptomycin (Aminoglycosides) and Azithromycin (Macrolide). On the other hand, the isolates were found to be $100 \%$ resistant to
Tetracycline and Penicillin class of antibiotics namely, Penicillin, Ampicillin and Amoxyclav. Multiple antibiotic resistance (MAR) index for different A. hydrohila isolates namely, $A h 2, A h 7$ and $A h 9$ were found to be $0.5,0.4$ and 0.4 respectively.

In the present study, it is evident from Table 3 that all the A. hydrophila isolates were $100 \%$ susceptible to Fluroquinolone class of antibiotics comprising of Ciprofloxacin, Ofloxacin and Norfloxacin. The findings of this study match well with the previous reports that Aeromonas hydrophila isolated from various fresh water fishes from Syria, Bangladesh and Rajasthan were $100 \%$ susceptible to Ciprofloxacin (Daood, 2011; Lijon et al., 2015; Monir et al., 2016; Rawal et al., 2016). However, few researchers of different regions have reported varying percentage of resistance for A. hydrophilla isolates towards Ciprofloxacin i.e., $31.75 \%$ in South China (Yang et al., 2017), 6.25\% at Dhaka in Bangladesh (Sarder et al., 2016) and $30.8 \%$ at Odisha and Andhra Pradesh in India (Samal et al., 2014). A report by Samal et al., (2014) on $100 \%$ susceptibility to Ofloxacin and only $15.4 \%$ resistance to Norfloxacin corroborates our findings. 
The strains under this study were also found to be $100 \%$ sensitive towards Gentamycin and $33 \%$ sensitive and $67 \%$ intermediate towards Streptomycin, although both of them belong to Aminoglycosides class of antibiotics. Varying level of resistance of A. hydrophila has been reported towards Streptomycin i.e. $8.7 \%$ resistance in Southern India (Vivekanandhan et al., 2002), $18.1 \%$ in Turkey (Yucel et al., 2005), 7.7\% at Odisha and Andhra Pradesh in India (Samal et al., 2014), 25\% in Bangladesh (Sarder et al., 2016), $87.5 \%$ at Rajasthan in India (Rawal et al., 2016) and 79.37\% in South China (Yang et al., 2017). On the other hand, our findings as $100 \%$ sensitive towards Gentamycin corroborates with many others earlier reports (Lijon et al., 2015; Monir et al., 2016; Rawal et al., 2016; Sarder et al., 2016; Yang et al., 2017). However, there are certain deviations such as $7.5 \%$ resistance reported in Southern India (Vivekanandhan et al., 2002), 54\% in Turkey (Yucel et al., 2005), 4.69\% in Syria (Daood, 2011) and 30.8\% at Odisha and Andhra Pradesh in India (Samal et al., 2014).

It is clear from the Table 3 that the $A$. hydrophila isolates used in this study were $100 \%$ resistant towards Tetracycline. Varying level of resistance have been reported for Tetracycline elsewhere across the globe i.e. $51.4 \%$ in Southern India (Vivekanandhan et al., 2002), 36.3\% in Turkey (Yucel et al., 2005), 53.12\% in Syria (Daood, 2011), 38.5\% in Odisha and Andhra Pradesh (Samal et al., 2014), 36\% and 37.5\% in Bangladesh (Monir et al., 2016; Sarder et al., 2016) respectively, $88.89 \%$ in South China (Yang et al., 2017). On the other hand, $100 \%$ susceptibility has been reported towards Tetracycline for $A$ hydrophilla isolated from water samples of Lake Fateh Sagar and Lake Pichhola of Udaipur, Rajasthan in India (Rawal et al., 2016) and catfish at Marang River in Malaysia (Laith and Najiah, 2014).
In accordance to the findings of this study, very low or almost zero resistance of $A$ hydrophila isolates has been reported for Azithromycin by (Samal et al., 2014; Lijon et al., 2015; Monir et al., 2016; Yang et al., 2017). Similarly, many researchers (Yucel et al., 2005; Daood, 2011; Laith and Najiah, 2014; Samal et al., 2014; Lijon et al., 2015; Monir et al., 2016; Rawal et al., 2016; Sarder et al., 2016; Yang et al., 2017) have reported $100 \%$ resistance for Penicillin class of antibiotics namely, Penicillin, Ampicillin and Amoxyclav which are also similar to the findings of this study.

Out of 10 antibiotics tested in this study, all strains were found to be resistant to more than 3 antibiotics. That's why the MAR index of all these strains were found to be more than 0.2 , which indicates the elevated rate of use or the high-risk exposure of antibiotics for animal treatment (Laith and Najiah, 2014). Bacteria become resistant to multiple antibiotics, may be due to presence of antibiotic resistant genes, that may be chromosomal or extrachromosomal (Subashkumar et al., 2007; Lukkana et al., 2012). However, if it is extrachromosomal and mobile in nature like plasmid mediated then there is every possibility of its transmission to other dreaded pathogens in the environment and cause serious menace (Sahu et al., 2010). The extensive and misuse of antimicrobial drugs accelerates the emergence of drug-resistant strains. Resistance of a microorganism to an antimicrobial drug is a global concern, because this resistance threatens the effective prevention and treatment of the infections caused by the pathogens both in human and animals.

To summarize, the findings of the study indicate the involvement of multiple antibiotic resistant Aeromonas hydrophila as one of the major pathogen in the disease outbreak of 
cultured Indian major carps. The study further affirms the superiority of molecular characterization in precise identification of Aeromonas hydrophila over the conventional microbiological and biochemical methods.

\section{Acknowledgment}

The financial assistance provided by NFDB, Hyderabad through ICAR-NBFGR, Lucknow in the form of NSPAAD (National Surveillance Programme for Aquatic Animal Diseases) (Sub Project-20) is greatly acknowledged. The physical facilities provided by the Director, College of Fisheries (OUAT), Rangailunda, Odisha to carry out the research work is also thankfully acknowledged.

\section{References}

Abbott, S. L., Cheung, W. K. and Janda, J. M. 2003. The genus Aeromonas: biochemical characteristics, atypical reactions, and phenotypic identification schemes. Journal of Clinical Microbiology. 41(6): 2348-2357. doi:10.1128/jcm.41.6.2348-2357.2003

Albert, M. J., Ansaruzzaman, M., Talukder, K. A., Chopra, A. K., Kuhn, I., Rahman, M., Faruque, A. S., Islam, M. S., Sack, R. B. and Mollby, R. 2000. Prevalence of enterotoxin genes in Aeromonas spp. isolated from children with diarrhea, healthy controls, and the environment. Journal of Clinical Microbiology. 38(10): 3785-3790.

Ali, M. F., Rashid, D. M. M., Rahman, M. M. and Haque, M. N. 2014. Pathogenicity of Aeromonas hydrophila in Silver Carp Hypophthalmichthys molitrix and its Control Trial. IOSR Journal of Agriculture and Veterinary Science. 7(6): 21-24.

Ashiru, A. W., Uaboi-Egbeni, P. O., Oguntowo, J. E. and Idika, C. N. 2011.
Isolation and Antibiotic Profile of Aeromonas Species from Tilapia Fish (Tilapia nilotica) and Catfish (Clarias betrachus). Pakistan Journal of Nutrition. 10(10): 982-986.

Awan, M. B., Ahmed, M. M., Bari, A. and Saad, A. M. 2005. Biochemical characterization of the Aeromonas species isolated from food and environment. Pakistan. J. Physiol. 1(12): 10-21.

Bauer, A. W., Kirby, W. M., Sherris, J. C. and Turck, M. $1966 . \quad$ Antibiotic susceptibility testing by a standardized single disk method. American Journal of Clinical Pathology. 45(4): 493-496.

Cao, H., He, S., Lu, L. and Hou, L. 2010. Characterization and phylogenetic analysis of the bitrichous pathogenic Aeromonas hydrophila isolated from diseased Siberian sturgeon. The Israeli Journal of Aquaculture - Bamidgeh. 62(3): 181-188.

Chu, W. H. and Zhu, W. 2010. Isolation of Bdellovibrio as biological therapeutic agents used for the treatment of Aeromonas hydrophila infection in fish. Zoonoses and Public Health. 57(4): 258264. doi:10.1111/j.18632378.2008.01224.x

CLSI. 2018. Performance standards for antimicrobial disk susceptibility tests. $13^{\text {th }}$ ed. CLSI standard M02. Wayne, PA: Clinical and Laboratory Standards Institute.

Daood, N. 2011. Isolation and Antibiotic Susceptibility of Aeromonas spp. From Freshwater Fish Farm and Farmed Carp (Dam of 16 Tishreen, Lattakia). Damascus University Journal for Basic Sciences. 28(1): 27-39.

FAO. 2018. The State of World Fisheries and Aquaculture 2018 - Meeting the sustainable development goals. Rome, License: CC BY-NC-SA 3.0 IGO.

FDA. 1998. Food and Drug Administration. 
"Chapter XI: Aquaculture Drugs." In: Fish and Fishery Products Hazards and Controls Guide. (Second Edition). FDA: Washington, D.C. 115-132.

Guz, L. and Kozińska, K. 2004. Antibiotic susceptibility of Aeromonas hydrophila and Aeromonas sobria isolated from farmed carp (Cyprinus carpio L.). Bulletin of The Veterinary Institute in Pulawy. 48: 391-393.

Hossain, S., Heo, H., De Silva, B. C. J., Wimalasena, S., Pathirana, H. and Heo, G. J. 2017. Antibacterial activity of essential oil from lavender (Lavandula angustifolia) against pet turtle-borne pathogenic bacteria. Laboratory Animal Research. 33(3): 195-201.

Hu, M., Wang, N., Pan, Z. H., Lu, C. P. and Liu, Y. J. 2012. Identity and virulence properties of Aeromonas isolates from diseased fish, healthy controls and water environment in China. Letters in Applied Microbiology. 55(3): 224-233.

Janda, J. M. and Abbott, S. L. 2010. The genus Aeromonas: taxonomy, pathogenicity, and infection. Clinical Microbiology Reviews. 23(1): 35-73. doi:10.1128/CMR.00039-09

Jeeva, S., J., L. P. N. C., Brindha, R. J. and Vasundevan, A. 2013. Studies on antibiotic subsceptibility of Aeromonas hydrophila Isolated from gold fish (Carassius auratus). International Journal of Current Microbiology and Applied Sciences. 2(12): 7-13.

Jenkins, J. A. and Taylor, P. W. 1995. An alternative bacteriological medium for the isolation of Aeromonas spp. Journal of Wildlife Diseases. 31(2): 272-275.

Jorgensen, J. H. and Ferraro, M. J. 2009. Antimicrobial susceptibility testing: a review of general principles and contemporary practices. Clinical Infectious Diseases. 49(11): 1749-1755.

Jorgensen, J. H. and Turnidge, J. D. 2007. Antibacterial susceptibility tests: dilution and disk diffusion methods. In: Murray PR, Baron EJ, Jorgensen $\mathrm{JH}$, Landry ML, Pfaller MA, (eds). Manual of Clinical Microbiology. 9th ed. Washington, DC: American Society for Microbiology. Pp. 1152-72.

Khuntia, B. K. 2011. Basic Microbiology An Illustrated Laboratory Manual. Daya Publishing House, Delhi. Pp. 131-192.

Kimura, M. 1980. A simple method for estimating evolutionary rates of base substitutions through comparative studies of nucleotide sequences. Journal of Molecular Evolution. 16(2): 111-120.

Kumar, R., Pande, V., Singh, L., Sharma, L., Saxena, N., Thakuria, D., Singh, A. K. and Sahoo, P. K. 2016. Pathological Findings of Experimental Aeromonas hydrophila Infection in Golden Mahseer (Tor putitora). Fisheries and Aquaculture Journal. 7(1): 160.

Kumar, S., Stecher, G., Li, M., Knyaz, C. and Tamura, K. 2018. MEGA X: Molecular Evolutionary Genetics Analysis across Computing Platforms. Molecular Biology and Evolution. 35(6): 15471549. doi:10.1093/molbev/msy096

Kupfer, M., Kuhnert, P., Korczak, B. M., Peduzzi, R. and Demarta, A. 2006. Genetic relationships of Aeromonas strains inferred from $16 \mathrm{~S}$ rRNA, gyrB and $\mathrm{rpoB}$ gene sequences. International Journal of Systematic and Evolutionary Microbiology. 56: 2743-2751.

Laith, A. R. and Najiah, M. 2014. Aeromonas hydrophila: Antimicrobial Susceptibility and Histopathology of Isolates from Diseased Catfish, Clarias gariepinus (Burchell). Journal of Aquaculture Research and Development. 05(02):1-7.

Lamy, B., Laurent, F., Kodjo, A., Roger, F., Jumas-Bilak, E. and Marchandin, $\mathrm{H}$. 2012. Which antibiotics and breakpoints should be used for Aeromonas susceptibility testing? Considerations from a comparison of agar dilution and 
disk diffusion methods using Enterobacteriaceae breakpoints. European Journal Clinical Microbiology and Infectious Diseases. 31: 2369-2377.

Leung, T. L. F., Bates, A. E. and Dulvy, N. 2013. More rapid and severe disease outbreaks for aquaculture at the tropics: implications for food security. Journal of Applied Ecology. 50(1): 215-222.

Lijon, M., Khatun, M., Islam, A., Khatun, M. and Islam, M. 2015. Detection of multidrug resistance Aeromonas hydrophila in farm raised fresh water prawns. Journal of Advanced Veterinary and Animal Research. 2(4): 469-474.

Lukkana, M., Wongtavatchai, J. and Chuanchuen, R. 2012. Class 1 integrons in Aeromonas hydrophila isolates from farmed Nile tilapia (Oreochromis nilotica). Journal of Veterinary Medical Science. $\quad 74(4)$ : 435-440. doi:10.1292/jvms.11-0441

Monir, M. S., Rahman, M. H., Kabir, M. L., Khatun, M. S., Reza, A. K. M. A., Rahman, F. and Borty, S. C. 2016. Isolation, molecular identification and antibiotic susceptibility profile of Aeromonas hydrophila from cultured indigenous Koi (Anabus testudineus) of Bangladesh. Asian Journal of Medical and Biological Research. 2(2): 332-340.

Nahar, S., Rahman, M. M., Ahmed, G. U., and Faruk, M. A. R. 2016. Isolation, identification, and characterization of Aeromonas hydrophila from juvenile farmed pangasius (Pangasianodon hypophthalmus). International Journal of Fisheries and Aquatic Studies. 4(4): 5260.

Palu, A. P., Gomes, L. M., Miguel, M. A., Balassiano, I. T., Queiroz, M. L., Freitas-Almeida, A. C. and de Oliveira, S. S. 2006. Antimicrobial resistance in food and clinical Aeromonas isolates. Food Microbiology. 23(5): 504-509.

Pradhan, P. K., Sood, N., Swaminathan, T. R. and Praveena, E. 2014. Collection, Preservation and Dispatch of materials for laboratory diagnosis of aquatic animal diseases In: Diagnostic Manual for Aquatic Animal Diseases of National Concern. Department of Animal Husbandary, Dairying and Fisheries, Ministry of Agriculture, Government of India, Krishi Bhavan, New Delhi, India. 87-92.

Rawal, I., Joshi, H. and Chaudhary, B. L. 2016. Isolation, Identification, and Antibiotics Resistance of Aeromonas spp. from Lakes of Udaipur (Rajasthan), India. Asian Journal of Pharmaceutics. 10(2): 132-136.

Rebecca, G. and Triplett, T. 1997. Murky Waters: Environmental Effects of Aquaculture in the United States. New York: Environmental Defence Fund.

Robinson, N., Baranski, M., Mahapatra, K. D., Saha, J. N., Das, S., Mishra, J., Das, P., Kent, M., Arnyasi, M. and Sahoo, P. K. 2014. A linkage map of transcribed single nucleotide polymorphisms in rohu (Labeo rohita) and QTL associated with resistance to Aeromonas hydrophila. BMC Genomics. 15: 541.

Sahoo, P. K. and Das, B. K. 2014. Infection with Aeromonas hydrohila In: Diagnostic Manual for Aquatic Animal Diseases of National Concern. Department of Animal Husbandary, Dairying and Fisheries, Ministry of Agriculture, Government of India, Krishi Bhavan, New Delhi, India. 23-25. Sahu, B., Nayak, A. K., Singh, S. D., Behera, B. K. and Dash, G. 2010. Preliminary characterization of multiple antibiotic resistant Escherichia coli isolated from fish processing plants. Asian Journal of Microbiology, Biotechnology and Environmental Sciences. 12(3): 603608.

Samal, S. K., Das, B. K. and Pal, B. B. 2014. Isolation, biochemical characterization, 
antibiotic susceptibility study of Aeromonas hydrophila isolated from freshwater fish. International Journal of Current Microbiology and Applied Sciences. 3(12): 259-267.

Sarder, H., Khan, T., Saha, M. L., Punom, N. J., Mandal, S. C. and Rahman, M. S. 2016. Prevalence and antibiotic susceptibility of Aeromonas hydrophila isolated from freshwater fishes. Journal of Fisheries. 4(3): 411-419.

Shotts, E. B., Jr. and Rimler, R. 1973. Medium for the isolation of Aeromonas hydrophila. Applied Microbiology. 26(4): 550-553.

Singh, U. 1997. Isolation and Identification of Aeromonas spp. from Ground Meats in Eastern Canada. Journal of Food Protection. 60(2): 125-130.

Sreedharan, K., Philip, R. and Singh, I. S. 2012. Virulence potential and antibiotic susceptibility pattern of motile aeromonads associated with freshwater ornamental fish culture systems: a possible threat to public health. Brazilian Journal of Microbiology. 43(2): 754-765.

Subashkumar, R., Thayumanavan, T., Vivekanandhan, G. and Lakshmanaperumalsamy, P. 2007. Occurrence of Multiple Antibiotic
Resistance among Children Diarrhoeal Isolates of Aeromonas hydrophila. Research Journal of Microbiology. 2(1): 58-65.

Thiyagarajan, P., Bhavani, A. L., Ebbie, M. G., and Chandra, G. 2014. A study on the control of Aeromonas hydrophila infection in the cat fish by medicinal plants. Scholars Academic Journal of Bioscieneces. 2(2): 144-150.

Vivekanandhan, G., Savithamani, K., Hatha, A. A. and Lakshmanaperumalsamy, P. 2002. Antibiotic resistance of Aeromonas hydrophila isolated from marketed fish and prawn of South India. International Journal of Food Microbiology. 76(1-2): 165-168.

Yang, Y., Miao, P., Li, H., Tan, S., Yu, H. and $\mathrm{Yu}, \mathrm{H}$. 2017. Antibiotic susceptibility and molecular characterization of Aeromonas hydrophila from grass carp. Journal of Food Safety. 10: 1-6. doi:10.1111/JFS.12393

Yucel, N., Aslim, B. and Beyatli, Y. 2005. Prevalence and resistance to antibiotics for Aeromonas species isolated from Retail fish in Turkey. Journal of Food Quality. 28(4): 313-324.

\section{How to cite this article:}

Chandravanshi, P., S. K. Udgata, J. Kumari, B. Sahu and Pashupalaka, N. C. 2020. Isolation and Characterization of Multiple Antibiotic Resistant A. hydrophila causing Mortality of Indian Major Carps in Ganjam District, Odisha. Int.J.Curr.Microbiol.App.Sci. 9(12): 562-574. doi: https://doi.org/10.20546/ijcmas.2020.912.068 